\title{
Nanomagnetite- and Nanotitania-Incorporated Polyacrylonitrile Nanofibers for Simultaneous Cd(II)- and As(V)-Ion Removal Applications
}

\author{
Induni W. Siriwardane, Chanaka Sandaruwan, Rohini M. de Silva, Gareth R. Williams, \\ Sebastian J. Gurgul, Karolina Dziemidowicz, and K. M. Nalin de Silva*
}

Cite This: ACS Omega 2021, 6, 28171-28181

Read Online

ABSTRACT: This work reports the fabrication of nanomagnetiteand nanotitania-incorporated polyacrylonitrile nanofibers (MTPANs) by an electrospinning process, which has the potential to be used as a membrane material for the selective removal of $\mathrm{Cd}(\mathrm{II})$ and $\mathrm{As}(\mathrm{V})$ in water. The fiber morphology was characterized by scanning electron microscopy (SEM). The incorporation of nanomagnetite and nanotitania in the composite fiber matrix was confirmed by energy-dispersive X-ray spectroscopy (EDX), X-ray diffraction (XRD), and Fourier transform infrared (FT-IR) spectroscopy. The fibers doped with nanomagnetite and nanotitania (MPAN and TPAN fibers, respectively), as well as MTPAN and neat polycrylonitrile (PAN) fibers, after thermally stabilizing at 275 ${ }^{\circ} \mathrm{C}$ in air, were assessed for their comparative As(V)- and Cd(II)-ion

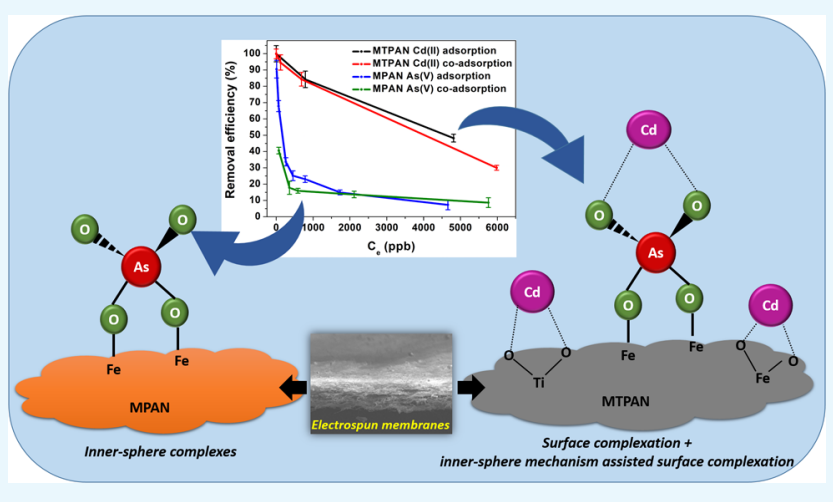
removal capacities. The isotherm studies indicated that the highest adsorption of Cd(II) was shown by MTPAN, following the Langmuir model with a $q_{\mathrm{m}}$ of $51.5 \mathrm{mg} / \mathrm{m}^{2}$. On the other hand, MPAN showed the highest As(V)adsorption capacity, following the Freundlich model with a $K_{\mathrm{F}}$ of 0.49 . The mechanism of adsorption of both $\mathrm{Cd}(\mathrm{II})$ and As(V) by fibers was found to be electrostatically driven, which was confirmed by correlating the point of zero charges (PZC) exhibited by fibers with the pH of maximum ion adsorptions. The As(V) adsorption on MPAN occurs by an inner-sphere mechanism, whereas Cd(II) adsorption on MTPAN is via both surface complexation and an $A s(V)$-assisted inner-sphere mechanism. Even though the presence of coexistent cations, $\mathrm{Ca}(\mathrm{II})$ and $\mathrm{Mg}(\mathrm{II})$, has been shown to affect the $\mathrm{Cd}(\mathrm{II})$ removal by MTPAN, the MTPAN structure shows $>50 \%$ removal efficiency even for minute concentrations $(0.5 \mathrm{ppm})$ of $\mathrm{Cd}$ (II) in the presence of high common ion concentrations (10 ppm). Therefore, the novel polyacrylonitrile-based nanofiber material has the potential to be used in polymeric filter materials used in water purification to remove $\mathrm{As}(\mathrm{V})$ and $\mathrm{Cd}(\mathrm{II})$ simultaneously.

\section{INTRODUCTION}

The engineering of advanced materials for water purification applications is an area of research that has been extensively explored. Conventional nonmembrane techniques for water purification include multistep coagulation, flocculation, sedimentation, filtration, ion exchange, ozone treatment, precipitation, adsorption, and disinfection. ${ }^{1-7}$ These conventional methods have a number of drawbacks, which can be overcome by novel membrane-based technologies. ${ }^{8}$ Membrane systems give improved selectivity, high separation efficiency, high stability, and the possibility of different modes of separation such as adsorption and ion exchange. 9 They can also effectively remove microorganisms and organic pollutants without producing any harmful secondary pollutants. ${ }^{8}$ As a result, a number of different membrane types, including organic polymers, inorganic materials (such as ceramics, oxides, and metals), and mixed-matrix or composite systems, have been investigated for water purification. It is recognized that polymer membranes are generally more favorable in membrane technology due to their high mechanical, ${ }^{8}$ thermal, ${ }^{8}$ chemical, and corrosion resistance. ${ }^{10}$ Polymeric nanofiber membranes are further advantageous in terms of their high surface-tovolume ratios and other special characteristics such as the possibility of introducing selectivity for target impurities by surface modification during synthesis. ${ }^{11}$

Electrospinning is one route of producing polymer-based nanofibers. The resultant electrospun nanofibrous membranes (ENMs), having pore sizes ranging from nanometers to

Received: August 7, 2021

Accepted: September 29, 2021

Published: October 14, 2021 
micrometers, with interconnected open pore structures are very attractive in water purification due to their high porosity, $^{12}$ high permeability, ${ }^{13}$ and high surface area per unit volume. ${ }^{12}$ ENMs are often considered to be one of the most versatile, simple, and efficient modes of membrane technology. ${ }^{8}$ Electrospun membranes commonly explored in water treatment include those constructed from polyvinylidene fluoride, ${ }^{14,15}$ polysulfone, ${ }^{16,17}$ polyacrylonitrile (PAN), ${ }^{8,18}$ polyvinyl alcohol, ${ }^{8,19}$ cellulose acetate, $^{20}$ and polyurethane. $^{21}$ Of these polymers, electrospun PAN fibers have attracted much attention owing to their ability to capture a wide range of pollutants including inorganic, ${ }^{22,23}$ organic, ${ }^{24-26}$ and biological contaminants. $^{27,28}$ To improve the filtration properties of PAN membranes, various chemical treatment methods have been employed to enhance hydrophilicity, ${ }^{29}$ flux, ${ }^{30-33}$ and mechanical and thermal properties ${ }^{32}$ and also to make them more fouling-resistant. ${ }^{33-35}$

The optimization of PAN-based membranes to achieve high metal-ion adsorption capacities in water treatment has typically been achieved by functionalizing fibers. Amination is one of the most commonly used strategies, and PAN fibers functionalized with diethylenetriamine have shown a higher adsorption capacity for $\mathrm{Zn}^{2+}$ and $\mathrm{Fe}^{3+}$ ions than their nonfunctionalized counterparts. $^{36}$ Similarly, ammonium molybdophosphate functionalized polyacrylonitrile ENMs exhibit high removal capacities for $\mathrm{Co}^{2+}, \mathrm{Sr}^{2+}$, and $\mathrm{Cs}^{+} .{ }^{37}$ In addition, hydrazinemodified PAN fibers have shown increased adsorption of $\mathrm{Cu}^{2+}$ and $\mathrm{Pb}^{2+} \cdot{ }^{38}$ The formation of metal oxide nanoparticle composites of PAN is another method that can be used to enhance their metal-ion adsorption capacity. High $\mathrm{Pb}^{2+}$ removal capacity has been noted with PAN-silica nanosphere systems, ${ }^{39}$ while PAN doped with a mixture of titania and silica nanoparticles has been reported to be potent in adsorbing As(III) and As(V). ${ }^{40}$ The potential of titania-functionalized PAN systems in photocatalytic membrane reactors for water purification has also been demonstrated. ${ }^{41,42}$ Further, zirconium-manganese oxide/PAN composite spheres have been used in $\mathrm{Sr}^{+}$adsorption ${ }^{43}$ and iron(III) chloride-doped porous PAN nanofibers in $\mathrm{Cr}$-ion removal. ${ }^{44}$ Additionally, the doping of PAN fibers with minerals such as pumice ${ }^{45}$ and halloysite $^{32}$ has also been identified as competent materials for removing heavy metal ions.

In many of the reported studies, the functionalization of PAN fibers has been targeted for the capturing of either cations or anions. However, a membrane that is capable of capturing both cations and anions is significantly more attractive for practical water purification applications. Hence, the objective of this study is to fabricate a PAN-based membrane system that is able to adsorb both arsenic and cadmium ions simultaneously since these two ions have been identified as potential risk factors for chronic kidney disease of unknown etiology $(\mathrm{CKDu})$, a major problem in Sri Lanka affecting more than 100000 people in the country. ${ }^{46,47}$ For this purpose, the PAN fibers were doped with both anatase and magnetite, and this is the first report on the fabrication of PAN nanofibers doped simultaneously with both magnetite and anatase. In a previous study, a hybrid structure consisting of $\mathrm{Fe}_{3} \mathrm{O}_{4}$ and $\mathrm{TiO}_{2}{ }^{48}$ was used for arsenic adsorption. Moreover, the use of goethite for the simultaneous removal of arsenate and cadmium ions has been previously explored. ${ }^{49}$ However, the practical use of a nanomaterial structure alone in water purification applications remains challenging. Even though a system of activated carbon fibers doped with bulk magnetite ${ }^{50}$ has been reported for arsenic adsorption, no report is available for testing a similar type of PAN fiber system doped with binary metal oxide nanoparticles to simultaneously remove $\mathrm{As}(\mathrm{V})$ and $\mathrm{Cd}(\mathrm{II})$. The fabrication of such a composite nanofiber structure of magnetite and titania nanoparticles in PAN makes it practical for use in water purification applications. In other words, the novelty of this work remains not only in composite fiber materials but also its application in removing dual ions with opposite electrical charges. Further, the nanoparticles embedded in a polymeric matrix have lesser chances of being leached out during their use. A systematic optimization of the electrospinning parameters, carbonization conditions of the nanomagnetite and nanotitania-doped PAN fibers, and adsorption conditions are also reported here.

\section{RESULTS AND DISCUSSION}

2.1. Optimization of MTPAN Fiber Electrospinning Parameters. During the spinning of $6 \%(\mathrm{w} / \mathrm{v})$ polymer/ nanoparticle suspensions at $10 \mu \mathrm{L} / \mathrm{min}$ and with an electrode distance of $20 \mathrm{~cm}$, when the applied voltage was increased from 15 to $25 \mathrm{kV}$, the fiber diameter was reduced from $1-3$ $\mu \mathrm{m}$ to $800-400 \mathrm{~nm}$ (Supporting Information, Figure S1). This occurs as with the increase in voltage, the electrostatic repulsive force on the charged jet increases, thereby narrowing the fiber diameter. ${ }^{51}$ Further, bead formation was also minimized with increased applied voltage (see Figure S1) due to the enhanced drawing of the polymer jet. ${ }^{52}$ Hence, 25 $\mathrm{kV}$ was selected as the optimal voltage for the spinning of titania- and magnetite-doped polyacrylonitrile fibers.

Spinning of $7 \%(\mathrm{w} / \mathrm{v})$ suspensions at $25 \mathrm{kV}$ and a $4 \mu \mathrm{L} / \mathrm{min}$ flow rate with electrode distances of 12,15 , and $20 \mathrm{~cm}$ resulted in fibers with dimensions of $3,1-3$, and $1-2 \mu \mathrm{m}$, respectively (Figure S2). This observation is consistent with previous reports, where little longer distances are known to favor thinner fibers due to the additional drawing time, which allows the jet to become narrow further, hence giving rise to thinner fibers. ${ }^{52}$ Subsequently, the optimal working distance selected for the MTPAN fiber spinning process was thus set at $20 \mathrm{~cm}$.

Morphological analyses of the fibers spun at different polymer concentrations at $25 \mathrm{kV}$ with a $4 \mu \mathrm{L} / \mathrm{min}$ flow rate and a distance of $20 \mathrm{~cm}$ indicated that even though bead formation is minimized with increased polymer concentration, the fiber size also tends to increase (Figure S3). Hence, 6\% $(\mathrm{w} / \mathrm{v})$ was selected as the optimal concentration, where a reasonable balance between the fiber diameter and the minimal bead formation could be achieved.

Next, the flow rate of the $6 \%(\mathrm{w} / \mathrm{v})$ polymer suspension was varied from 4 to $10 \mu \mathrm{L} / \mathrm{min}$ while having a constant $25 \mathrm{kV}$ voltage and a $20 \mathrm{~cm}$ working distance. The fiber dimensions obtained were 500-1000, 300, and 100-200 nm, respectively (Figure S4), indicating that the $10 \mu \mathrm{L} / \mathrm{min}$ rate gives optimum fibers with the narrowest fiber diameters. The literature suggests that, for a given voltage, there is a corresponding feed rate at which a stable Taylor cone develops, resulting in the formation of more uniform fibers. ${ }^{52}$ In our case, it was observed that the flow rate of $10 \mu \mathrm{L} / \mathrm{min}$ facilitated the formation of fibers with the most favorable dimensions under the provided conditions.

2.2. Fiber Characterization. Figure 1 shows the morphologies of the as-synthesized MTPAN, MPAN, TPAN, and PAN fibers, fabricated at $25 \mathrm{kV}$ with a flow rate of $10 \mu \mathrm{L} /$ min and a working distance of $20 \mathrm{~cm}$ using polymer/ nanoparticle suspensions with a $6 \%(\mathrm{w} / \mathrm{v})$ total concentration. 

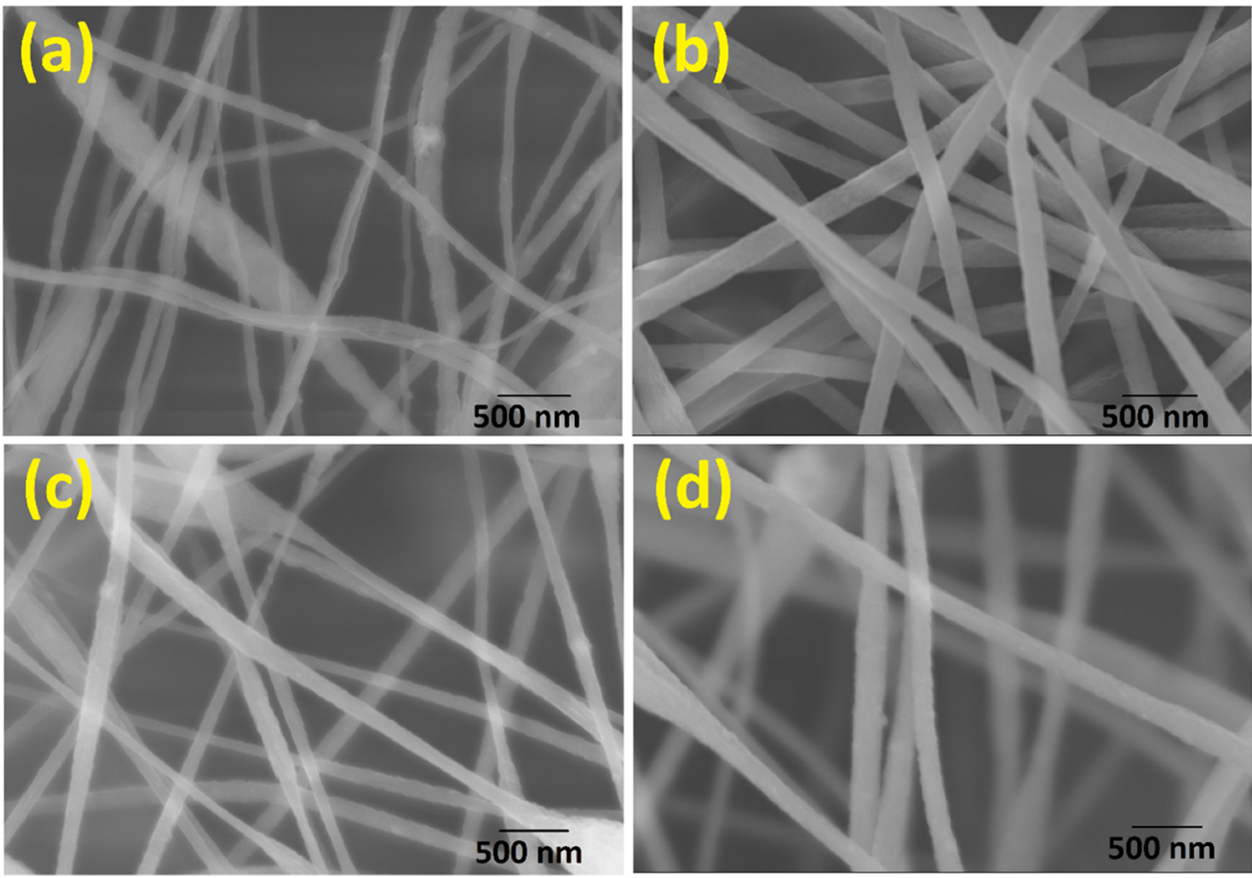

Figure 1. Scanning electron microscope images of (a) MTPAN, (b) MPAN, (c) TPAN, and (d) PAN.

All four fiber types show random distributions of uniform fibers, and there are nodes or bulges present at some points. The average diameters of MTPAN, MPAN, TPAN, and PAN fibers are $124 \pm 42,151 \pm 30,234 \pm 40$, and $245 \pm 49 \mathrm{~nm}$, respectively (see Figure S5 for histograms). The scanning electron microscopy (SEM) images of titania and magnetite nanoparticles are given in Figure S6, which confirms that both magnetite and titania nanoparticles are of size $<50 \mathrm{~nm}$, enabling them to be encapsulated within the polymer filament. The Brunauer-Emmett-Teller (BET) surface areas of MTPAN, MPAN, TPAN, and PAN fiber mats were 4.35, $4.28,2.53$, and $4.15 \mathrm{~m}^{2} / \mathrm{g}$, respectively (see Figure $\mathrm{S} 7$ for isotherms).

The energy-dispersive X-ray spectroscopy (EDX) analysis confirms the uniform distribution of the titania and magnetite nanoparticles within the fibers (Figure S8). However, concentrations of magnetite and titania are more prominent in areas with nodes. As far as MTPAN fibers are concerned, the distribution of both titania and magnetite along with fibers is visible and the existence of magnetite in bulges is more prominent, while in TPAN, the existence of $\mathrm{TiO}_{2}$ in those bulges is clear. Further, the comparison of Fourier transform infrared (FT-IR) spectra of the magnetite, titania, and MTPAN fibers (Figure S9) confirms the incorporation of the nanomaterials in the composite fibers. Vibration bands corresponding to $\mathrm{Fe}-\mathrm{O}$ at $596 \mathrm{~cm}^{-1}$ and $\mathrm{Ti}-\mathrm{O}$ at $552 \mathrm{~cm}^{-1}$ are clearly visible in the spectrum of the MTPAN fibers but are absent in that of pure PAN fibers. Also, the intensities of these peaks increase with increasing nanomaterial concentration in the composite fibers, which further supports their immobilization within the composite fibers.

$\mathrm{X}$-ray diffraction (XRD) patterns of the four fibers are given in Figure 2. All of the fiber samples show Bragg reflections at $2 \theta=17$ and $22^{\circ}$. These correspond to the (100) and (002) planes of the hexagonal lattice of polyacrylonitrile ${ }^{53}$ and are an indication of the crystalline microstructure of the PAN-based fibers. ${ }^{52,53}$ Reflections at $2 \theta=35.5$ and $43^{\circ}$ in the XRD pattern

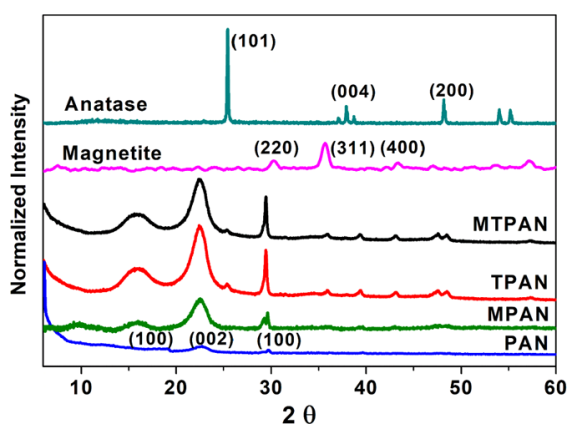

Figure 2. X-ray diffraction patterns of MTPAN, MPAN, TPAN, PAN, anatase, and magnetite.

of magnetite correspond to its (311) and (400) planes, respectively. ${ }^{54}$ These can also be identified in the XRD patterns of MPAN and MTPAN fibers. Reflections at $2 \theta=25$ and $48^{\circ}$ in the XRD pattern of anatase corresponding to its (101) and (200) planes ${ }^{55}$ are clearly observed in MTPAN and TPAN. Further, the Bragg reflections at $2 \theta=17,22$, and $29^{\circ}$ in the three composite fibers are very intense and sharp compared to those in the XRD pattern of the pure PAN fibers, which is indicative of the influence of the nanomaterials on the crystallinity of PAN-based fibers. It has been reported that when such composite fibers are formed, there is increased crystallization of the polymer filament during electrospinning. ${ }^{52}$

2.3. Thermal Stabilization. Thermogravimetric analysis of MTPAN, which was executed as stated in experimental section 4.0, is shown in Figure 3. According to the results, a weight loss of $19 \%$ of the MTPAN fibers was observed during the first oxidation step, while 58 and $73 \%$ weight losses were observed during the second and third steps, respectively. Upon heating up to $280{ }^{\circ} \mathrm{C}$, cyclization of the nitrile groups with the polymer backbone occurs, and during further heating up to $700{ }^{\circ} \mathrm{C}$, aromatization of the rings happens with dehydrogenation, whereas in the third step at $1100{ }^{\circ} \mathrm{C}$, graphitization 


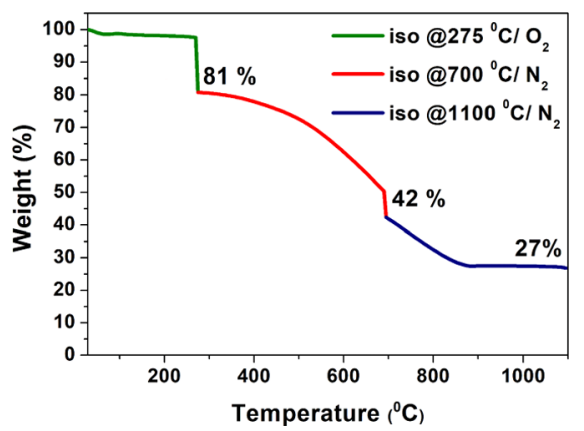

Figure 3. Thermogravimetric analysis of MTPAN fibers.

occurs with further dehydrogenation. ${ }^{56}$ However, reduction of the fiber yield to $27 \%$ is not favorable for practical concerns.

On the other hand, the Raman analysis provides more information about the extent of defects present in the structure based on the $I_{\mathrm{D}} / I_{\mathrm{G}}$ ratio, which is indicative of the number of defects present in a graphene-like structure. ${ }^{57}$ Usually, D and G bands are present in all polyaromatic hydrocarbons. ${ }^{58}$ The G peak is due to the bond stretching of $\mathrm{sp}^{2}$ atoms in both rings and chains. The $\mathrm{D}$ peak is due to the breathing modes of $\mathrm{sp}^{2}$ atoms in rings. ${ }^{58}$ Hence, the lesser the $\mathrm{sp}^{2}$ rings, the lower the $\mathrm{I}_{\mathrm{D}}$ with respect to $\mathrm{I}_{\mathrm{G}}$, thereby lowering the $I_{\mathrm{D}} / I_{\mathrm{G}}$ ratio. $^{57}$ According to the Raman analysis of the carbonized MTPAN fibers, the $I_{\mathrm{D}} / I_{\mathrm{G}}$ ratio varies from 1.32 to 1.28 to 1.18 during the three carbonization steps (Figure S10). Here, the change in the $I_{\mathrm{D}} / I_{\mathrm{G}}$ ratio from the first to the second step could be considered as less considerable, whereas when going through the third step, the change is somewhat substantial with a 0.1 change in the $I_{\mathrm{D}} / I_{\mathrm{G}}$ ratio. However, for practical concerns, a compromise has to be made between the thermal stabilization of the fibers and the fiber yield after carbonization. Thermal stabilization is important prior to using the electrospun PANbased fibers as it converts thermoplastic fibers to nonplastic cyclic or ladder compounds. ${ }^{56}$ This thermal stabilization is important to obtain nonsticky versatile membranes that are easy to handle during real-case applications. Therefore, thermally stabilized MTPAN fibers at $275{ }^{\circ} \mathrm{C}$ for $30 \mathrm{~min}$ were selected as the optimal condition for fiber preparation for this study as higher temperatures lower the yield.

2.4. Adsorption Studies. Adsorption studies were performed on MTPAN, MPAN, TPAN, and PAN fibers thermally stabilized at $275{ }^{\circ} \mathrm{C}$ in air.

2.4.1. Effect of $p H$. Figure S1la summarizes the As(V)

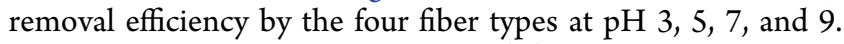
The highest removal efficiency for As (V) was shown by MPAN fibers at $\mathrm{pH} \mathrm{7,} \mathrm{whereas} \mathrm{TPAN} \mathrm{shows} \mathrm{the} \mathrm{lowest} \mathrm{removal}$ efficiency for As $(\mathrm{V})$. The maximum adsorption efficiency of $\mathrm{As}(\mathrm{V})$ by all four fiber types is observed around $\mathrm{pH}$ 6. This is similar to the observations in previous reports, where it has been identified that $\mathrm{H}_{2} \mathrm{AsO}_{4}{ }^{-}$ions are the prominent species at this $\mathrm{pH}$, as consecutive acid-dissociation constants of $\mathrm{H}_{3} \mathrm{AsO}_{4}$ are 2.2, 7.0, and 11.5. ${ }^{59}$ The estimated point of zero charge (PZC) values for MTPAN, MPAN, TPAN, and PAN fibers within the As $(\mathrm{V})$ solution are 7.0, 7.1, 6.0, and 6.8, respectively (Table 1), as calculated by the $\mathrm{pH}$ drift method (Figure S12a). The PZC is a concept related to the phenomenon of adsorption, and it describes the condition when the electrical charge density on a surface is zero. It is usually determined in relation to an electrolyte's $\mathrm{pH}$, and the $\mathrm{PZC}$ value is assigned to a given substrate. Even though PZC and the isoelectric point
Table 1. Point of Zero Charge of MTPAN, MPAN, TPAN, and PAN Fibers in As(V) and Cd(II) Solutions (Extracted from Figure S8)

\begin{tabular}{lcc} 
& \multicolumn{2}{c}{$\mathrm{pH}_{\mathrm{pzc}}$} \\
\cline { 2 - 3 } adsorbent & $\mathrm{As}(\mathrm{V})$ & $\mathrm{Cd}(\mathrm{II})$ \\
MTPAN & 7.0 & 5.2 \\
MPAN & 7.1 & 5.1 \\
TPAN & 6.0 & 3.0 \\
PAN & 6.8 & 5.0
\end{tabular}

(IEP) are closely related phenomena, they are not always the same. According to Jolivet, ${ }^{60}$ in the absence of positive or negative charges, the surface is best described by the point of zero charge, whereas if positive and negative charges are both present in equal amounts (e.g., amino acids), then this is the

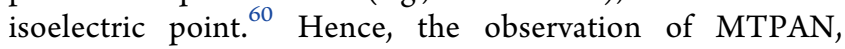
MPAN, and PAN surfaces giving the highest adsorption of As $(\mathrm{V})$ can be explained by the positively charged fiber surfaces existing between $\mathrm{pH} \mathrm{5-7}$ attracting $\mathrm{H}_{2} \mathrm{AsO}_{4}{ }^{-}$anions.

On the other hand, the maximum $\mathrm{Cd}(\mathrm{II})$ adsorption efficiency was observed with MTPAN at $\mathrm{pH} 9$ among the pHs tested, and the lowest adsorption was given by MPAN. This trend of observing a higher sorption with increasing $\mathrm{pH}$ (Figure S11b) agrees with the previously reported study. ${ }^{61}$ In our study, $\mathrm{pH}$ higher than 9 was not chosen as it will lead to the formation of $\mathrm{Cd}(\mathrm{OH})_{2}(\mathrm{~s})$ according to Ksp calculations. As summarized in Table 1, the estimated PZCs for MTPAN, MPAN, TPAN, and PAN fibers in the Cd(II) solution are 5.2, 5.1, 3.0, and 5.0, respectively (Figure S12b). Therefore, when the maximum adsorption of $\mathrm{Cd}$ (II) happens, all four fibers are negatively charged to attract $\mathrm{Cd}$ (II) cations. Hence, the main mechanism of adsorption for both $\mathrm{As}(\mathrm{V})$ and $\mathrm{Cd}(\mathrm{II})$ can be identified as being electrostatically driven.

Therefore, the experiments to understand the adsorption isotherms were conducted without any $\mathrm{pH}$ adjustments by dissolving $\mathrm{As}(\mathrm{V})$ and $\mathrm{Cd}(\mathrm{II})$ ions in an aqueous medium, for which the pHs were found to be around 7 and 6, respectively.

2.4.2. Adsorption Isotherms. To understand the adsorption phenomena, Langmuir (eq 1) and Freundlich (eq 2) isotherms were generated for MTPAN, MPAN, TPAN, and PAN fibers for both $\mathrm{As}(\mathrm{V})$ and $\mathrm{Cd}(\mathrm{II})$ (Figures S13 and S14).

$$
\begin{aligned}
& \frac{C_{\mathrm{e}}}{q_{\mathrm{e}}}=\frac{1}{K_{\mathrm{L}} q_{\mathrm{m}}}+\frac{C_{\mathrm{e}}}{q_{\mathrm{m}}} \\
& \ln q_{\mathrm{e}}=\ln K_{\mathrm{f}}+\frac{1}{n} \ln C_{\mathrm{e}}
\end{aligned}
$$

The term $C_{\mathrm{e}}(\mathrm{mg} / \mathrm{L})$ is the equilibrium concentration of the adsorbate in solution, $q_{\mathrm{e}}(\mathrm{mg} / \mathrm{g})$ is the equilibrium concentration of the adsorbate in the adsorbent, $q_{\mathrm{m}}(\mathrm{mg} / \mathrm{g})$ is the maximum equilibrium concentration of the adsorbate in the adsorbent (monolayer coverage of the surface), $K_{\mathrm{L}}(\mathrm{L} / \mathrm{mg})$ is a constant related to the heat of adsorption, $K_{\mathrm{F}}\left(\mathrm{mg}^{(1-1 / n)}\right.$ $\left.\mathrm{L}^{1 / n} \mathrm{~g}^{-1}\right)$ is related to the adsorption capacity of the adsorbent, and $1 / \mathrm{n}$ is a constant known as the heterogeneity factor, which is related to surface heterogeneity. ${ }^{59}$

According to the isotherm analysis (Figures S13 and S14), $\mathrm{As}(\mathrm{V})$ data is better matched with the Freundlich isotherm (Table 2). When comparing the Freundlich constants $\left(K_{\mathrm{F}}\right)$ of MTPAN, MPAN, TPAN, and PAN fibers for As $(V)$ adsorption, a key observation is that MPAN shows the highest As $(\mathrm{V})$ adsorption capacity compared to neat PAN fibers. This 
Table 2. Freundlich and Langmuir Isothermal Parameters for MTPAN, MPAN, TPAN, and PAN for As(V) and Cd(II) Adsorption

\begin{tabular}{|c|c|c|c|c|c|c|}
\hline \multirow[b]{2}{*}{ sample } & \multicolumn{3}{|c|}{ Freundlich isotherm $\mathrm{As}(\mathrm{V})$ adsorption } & \multicolumn{3}{|c|}{ Langmuir isotherm $\mathrm{Cd}(\mathrm{II})$ adsorption } \\
\hline & $1 / n$ & $K_{\mathrm{F}}\left(\mathrm{mg}^{(1-1 / n)} \mathrm{L}^{1 / n} \mathrm{~g}^{-1}\right)$ & $R^{2}$ & $q_{\mathrm{m}}\left(\mathrm{mg} / \mathrm{m}^{2}\right)$ & $K_{\mathrm{L}} \times 10^{3}\left(\mathrm{~L} / \mathrm{m}^{2}\right)$ & $R^{2}$ \\
\hline MTPAN & 0.78 & 0.195 & 0.965 & 51.54 & 0.194 & 0.995 \\
\hline MPAN & 0.22 & 0.492 & 0.992 & 24.46 & 0.088 & 0.993 \\
\hline TPAN & 0.87 & 0.026 & 0.984 & 41.74 & 0.042 & 0.963 \\
\hline PAN & 1.01 & 0.006 & 0.998 & 26.00 & 0.062 & 0.932 \\
\hline
\end{tabular}

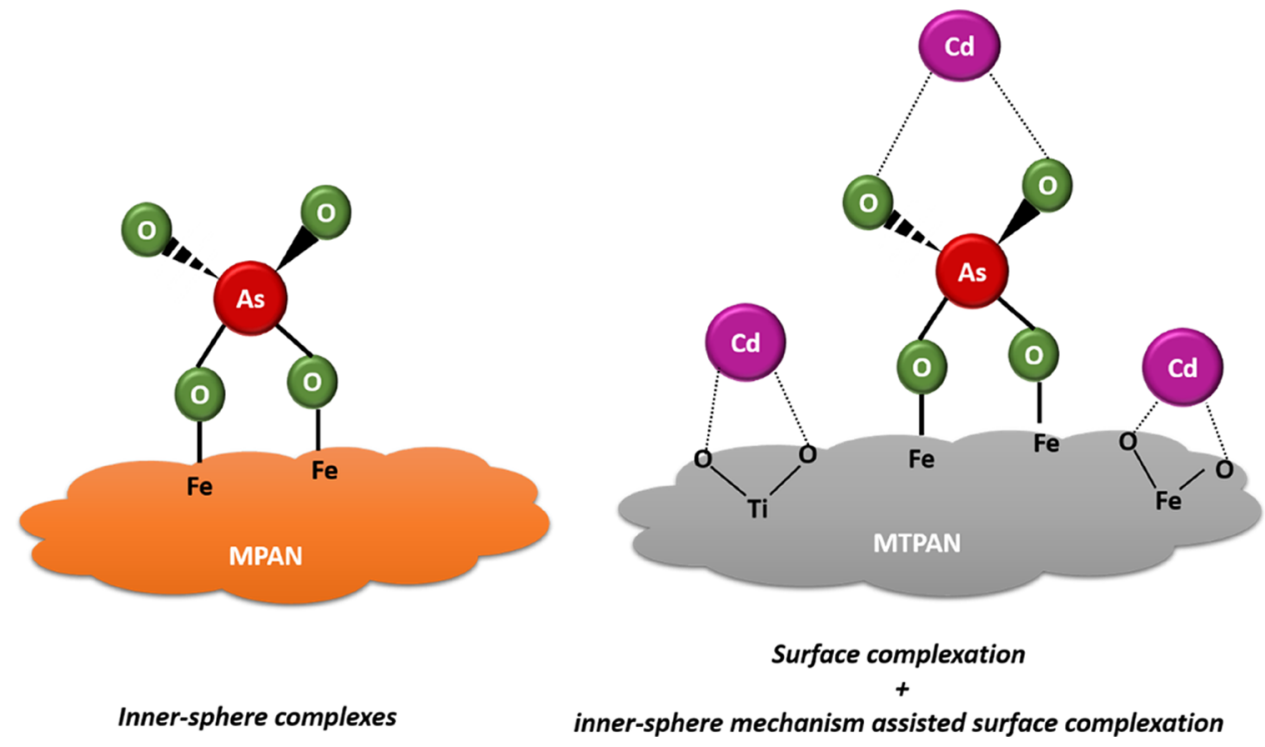

Figure 4. Adsorption mechanism of $\mathrm{As}(\mathrm{V})$ on $\mathrm{MPAN}$ and $\mathrm{Cd}(\mathrm{II})$ on MTPAN.

observation is consistent with the previous literature where magnetite was shown to absorb As $(\mathrm{V})$ by forming a binuclear bidentate (inner-sphere) complex. ${ }^{62}$ Further, TPAN also shows an enhanced As(V) adsorption compared to PAN even though that enhancement is not much prominent. The As $(V)$ adsorption by TPAN can again be attributed to the affinity of anatase for $\mathrm{As}(\mathrm{V})$ adsorption, which is again proven to occur via a bidentate binuclear complex formation. ${ }^{63}$ In other words, the results of this study provide a comparative study for the use of both magnetite and titania in removing $\mathrm{As}(\mathrm{V})$ by adsorption, where magnetite remains to be much promising for this purpose. However, when both anatase and magnetite are present in equimolar quantities, the adsorption capacity is in between PAN and MPAN. This can be explained by having a higher concentration of magnetite $(0.0005 \mathrm{~mol} / \mathrm{g})$ in the MPAN fiber than it is in the MTPAN fiber (each magnetite and anatase in $0.00025 \mathrm{~mol} / \mathrm{g}$ ). This observation further confirmed that the $\mathrm{As}(\mathrm{V})$ adsorption by magnetite under the given conditions is more prominent than that of anatase. Hence, for practical applications in As(V) removal, PAN fibers doped with magnetite nanoparticles would be better than MTPAN.

According to Table 2, adsorption data for Cd(II) with all four fiber types agree well with the Langmuir isotherm model. Based on the $q_{\mathrm{m}}$ values calculated, a higher adsorption capacity for Cd(II) is exhibited by TPAN than MPAN. It is also clear that the effect of magnetite showed very little improvement compared to PAN. Nevertheless, the MTPAN fibers show the highest adsorption of $\mathrm{Cd}(\mathrm{II})$, unlike in the case for $\mathrm{As}(\mathrm{V})$. Hence, a synergistic effect of both anatase and magnetite can be expected to exist, as both titania ${ }^{61}$ and magnetite ${ }^{64}$ have been shown to adsorb $\mathrm{Cd}(\mathrm{II})$ via surface complexation. Further, when both $\mathrm{As}(\mathrm{V})$ and $\mathrm{Cd}(\mathrm{II})$ are present together, As(V)-assisted $\mathrm{Cd}$ (II) adsorption mechanism on goethite occurs, as has been previously reported, ${ }^{49}$ which is also a possible mechanism for the enhanced $\mathrm{Cd}(\mathrm{II})$ adsorption observed here. Therefore, this study provides evidence for using multiple nanomaterial-doped PAN fibers for Cd(II) removal in practical scenarios. Further, the MTAPN fibers will serve the purpose of simultaneous removal of $\mathrm{Cd}$ (II) cations as well as $\mathrm{As}(\mathrm{V})$ anions. In addition, the surface complexed $\mathrm{Cd}$ (II) can be removed by the flushing mechanism, whereas the chemisorbed $\mathrm{As}(\mathrm{V})$ is the most likely to cause the fouling of membranes in practical applications. However, further research should be done to study the reusability of the membrane. For our further investigations, MPAN was used for As(V) adsorption and MTPAN was used for Cd(II) adsorption. Figure 4 summarizes the $\mathrm{As}(\mathrm{V})$ and $\mathrm{Cd}(\mathrm{II})$ adsorption mechanisms on MPAN and MTPAN, respectively.

Moreover, the isotherm parameters reported for As(V) and $\mathrm{Cd}$ (II) adsorption by the nanocomposite fibers in this study are lower than those reported for free $\mathrm{Fe}_{3} \mathrm{O}_{4}-\mathrm{TiO}_{2}{ }^{48}$ nanoparticle hybrids, goethite nanoparticles, ${ }^{49}$ and mixtures of carbon fibers and magnetite nanoparticles. ${ }^{50}$ This can be mainly attributed to the high availability of surface functional groups in the free nanoparticles compared to those in the composited polymeric fibers. However, embedding nanoparticles in the polymer matrix will have the advantage over using bulk nanoparticles by preventing the expulsion of nanoparticles into water streams, which is an important concern for real-world applications. 
The FT-IR spectra of MTPAN and MPAN after Cd(II) and As $(V)$ adsorption are given in Figure S15. The MTPAN after $\mathrm{Cd}$ (II) adsorption shows a band at $409 \mathrm{~cm}^{-1}$, which is absent from that of the MTPAN before adsorption, which is due to the $\mathrm{Cd}-\mathrm{O}$ bond. ${ }^{65}$ The As $(\mathrm{V})$ adsorption in the MPAN structure is also confirmed by the comparison of the FT-IR spectra before and after adsorption, where the shoulder around $696 \mathrm{~cm}^{-1}$ can be attributed to the adsorbed As(V). ${ }^{66}$ Further, the SEM images of MTPAN after Cd(II) adsorption and MPAN after As(V) adsorption are given in Figure S16, together with the EDX profiles. The fibers do not show any salt depositions (fouling signs) after adsorption studies, which is a positive implication. Moreover, the EDX spectra confirm the capturing of respective ions by the fibers, whereas the quantitative data are of no significance as they are site-specific. The heavy metal adsorption capacities calculated for the composite fibers used in this study are slightly lower than in some previous studies, ${ }^{48,52}$ which had used the neat nanomaterial for the adsorption study. This can be attributed to the fact that during the composite nanofiber formation by the spinning process, the available active sites (nanomaterial) per unit adsorbate mass are lowered compared to that of the neat nanomaterial. However, immobilization of the nanomaterial in a matrix material will be advantageous as it minimizes the leaching-out probability of the nanomaterial into water besides minimizing costing aspects.

2.4.3. Coadsorption of $A s(V)$ and $C d(I I)$. Figure 5 compares the removal efficiencies of $\mathrm{As}(\mathrm{V})$ by MPAN fibers and $\mathrm{Cd}(\mathrm{II})$

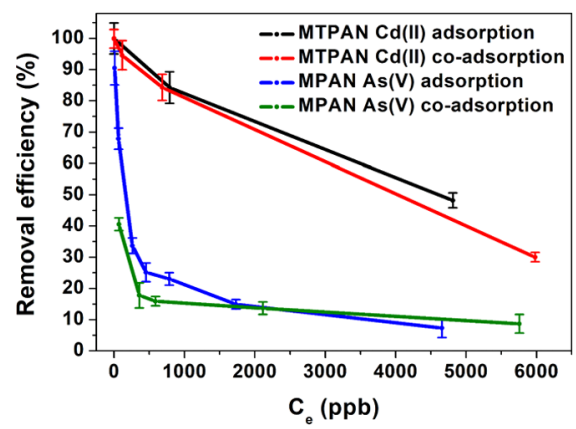

Figure 5. Comparison of the removal efficiencies of As(V) by MPAN and $\mathrm{Cd}(\mathrm{II})$ by MTPAN fibers from an equimolar mixture of $\mathrm{As}(\mathrm{V})$ and $\mathrm{Cd}(\mathrm{II})$.

by MTPAN fibers. In this experiment, as given under Section 4.7 , adsorption studies were carried out for individual ions as well as for a mixture of equimolar amounts of both As(V) and $\mathrm{Cd}(\mathrm{II})$. According to the results, the removal efficiency of Cd(II) remains almost the same irrespective of individual adsorption or coadsorption. However, the minor reduction observed when coadsorption happens can be attributed to the presence of $\mathrm{As}(\mathrm{V})$ with more affinity to magnetite, thereby nullifying the available adsorption sites for Cd(II). On the other hand, the $\operatorname{As}(\mathrm{V})$ adsorption by MPAN fibers exhibits a considerable reduction in their removal efficiencies, as clearly visible at lower equilibrium concentrations $\left(C_{\mathrm{e}}\right)$. This may be due to the surface complexation of electrostatically driven $\mathrm{Cd}(\mathrm{II})$ on magnetite, thereby hindering adsorption sites for $\mathrm{As}(\mathrm{V})$. The adsorption of $\mathrm{Cd}(\mathrm{II})$ and $\mathrm{As}(\mathrm{V})$ is further confirmed by the XPS analysis of the MTAPN (Figure S17) and MPAN (Figure S18) fiber structures. Figure 6 shows the XPS analysis of MTPAN and MPAN fibers after coadsorbing $\mathrm{Cd}(\mathrm{II})$ and As(V). The MTPAN fibers show prominent peaks corresponding to $\mathrm{Cd}$ at 405.4 and $412.2 \mathrm{eV}$ (Figure 6a), whereas MPAN shows prominent peaks corresponding to As at binding energies of 44.1 and $47.8 \mathrm{eV}$ (Figure 6b). These $\mathrm{As}(\mathrm{V})$ and $\mathrm{Cd}(\mathrm{II})$ coadsorption results are very closely correlated with a previous study that had used a pure goethite nanomaterial for simultaneous $\mathrm{As}(\mathrm{V})$ and $\mathrm{Cd}(\mathrm{II})$ adsorption, ${ }^{49}$ with regard to adsorption dynamics, effect of $\mathrm{pH}$, ionic strength, and the adsorption mechanism.

2.4.4. Effect of $\mathrm{Ca}(\mathrm{II})$ and $\mathrm{Mg}$ (II) lons on the MTPAN Adsorption Capacity. One of the major challenges in using membrane-based water filtration is the adsorption of competitive ions, which are present at higher concentrations compared to heavy metals. Generally, $\mathrm{Ca}$ (II) and $\mathrm{Mg}$ (II) ions are present as competitive ions in most part of the dry zone of Sri Lanka, where a higher number of CKDu cases is reported. According to the results, the MTPAN fiber system has the tendency to adsorb other positively charged co-ions such as $\mathrm{Ca}$ (II) and $\mathrm{Mg}$ (II). Therefore, it is imperative to assess the effect of such coexistent ions on the adsorption capacity of Cd(II) with MTPAN and As(V) with MPAN sorbent systems. Figure 7 shows the effect of $\mathrm{Ca}(\mathrm{II})$ and $\mathrm{Mg}$ (II) in water on $\mathrm{As}(\mathrm{V})$ and $\mathrm{Cd}(\mathrm{II})$ removal efficiencies at $\mathrm{pH} \mathrm{6-7.} \mathrm{It} \mathrm{is}$ intuitive to believe that $\mathrm{Mg}$ (II) and $\mathrm{Ca}$ (II) would interact with the sorbent in the same way as $\mathrm{Cd}$ (II) (due to the positive charge), whereas the mechanism should be different for $\mathrm{AsO}_{4}{ }^{3-}$ owing to its negative charge. Hence, it can be expected that the competitive adsorption of $\mathrm{Ca}$ (II) and $\mathrm{Mg}$ (II) would matter more for Cd(II) removal than for As(V) removal. As expected, the observed removal efficiency patterns show that
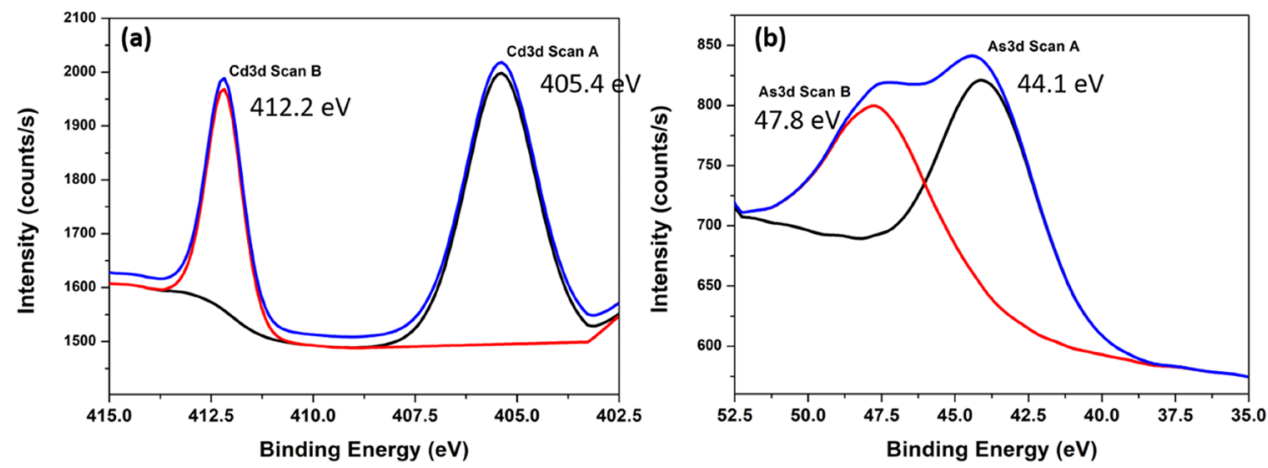

Figure 6. XPS analysis for the elemental composition of fiber surfaces (a) MTPAN and (b) MPAN after the adsorption of Cd(II) and As(V), respectively. 


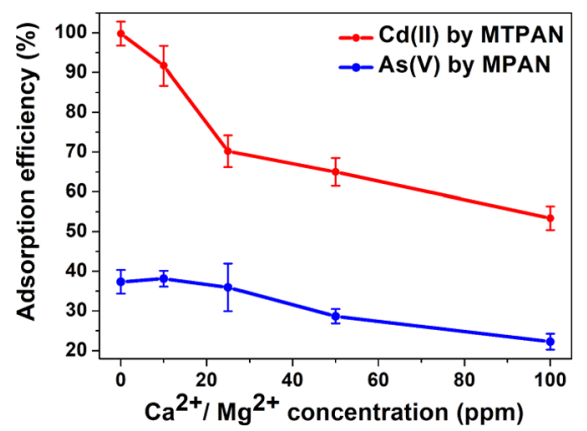

Figure 7. Effect of the co-ion concentration on the removal efficiencies of $\mathrm{As}(\mathrm{V})$ by MPAN and Cd(II) by MTPAN.

the removal efficiency of As(V) by the MPAN fibers shows only about $15 \%$ reduction, whereas that of $\mathrm{Cd}(\mathrm{II})$ is around $45 \%$, when the co-ion concentration increased from 0 to 100 ppm. A similar effect of $\mathrm{Ca}$ (II) on $\mathrm{Cd}$ (II) adsorption by zeolite has been shown in a previous study ${ }^{67}$ where it was attributed to the fact that a larger $\mathrm{Ca}$ (II) cation binds comparatively less tightly with water (lower hydration energy) and hence has a better chance to be adsorbed onto the adsorbent surface than staying as the hydrated form. However, the proposed MTPAN structure shows $>50 \%$ removal efficiency for lower concentrations $(0.5 \mathrm{ppm})$ of $\mathrm{Cd}(\mathrm{II})$, even in the presence of very high common ion concentrations $(10 \mathrm{ppm})$ - the conditions generally encountered in using these membranes in realworld water purification applications. Further, this study also shows that even though the performance of the proposed sorbent system slightly decreases with increasing ionic strength of the inlet water stream, notably it remains functional even at extremely high ionic strength conditions. Nonetheless, the adsorption dynamics of the targeted heavy metals can be affected by other ordinary cations commonly found in groundwater such as $\mathrm{Na}^{+}$and $\mathrm{K}^{+}$, anions such as $\mathrm{Cl}^{-}, \mathrm{F}^{-}$, $\mathrm{SO}_{4}{ }^{2-}$, and $\mathrm{PO}_{4}{ }^{3-}$ as well as by organic matter such as humic acid, citric acid, etc. Hence, it is worth carrying out a comprehensive analysis on these effects, which is beyond the scope of this study but worth recommending as future work in determining the potential of this novel material in real-world water purification applications.

\section{CONCLUSIONS}

Out of the four fiber types synthesized, the MTPAN fiber composite showed the highest adsorption capacity for Cd(II), whereas MPAN fibers showed the highest adsorption capacity for $\mathrm{As}(\mathrm{V})$ adsorption. The $\mathrm{Cd}(\mathrm{II})$ adsorption follows the Langmuir isotherm model, whereas the As(V) adsorption agrees well with the Freundlich isotherm pattern. The mechanism of adsorption of both $\mathrm{Cd}$ (II) and $\mathrm{As}(\mathrm{V})$ by fibers was found to be electrostatically driven, which was confirmed by correlating the point of zero charges (PZC) exhibited by fibers with the $\mathrm{pH}$ of maximum ion adsorptions. The As(V) adsorption on MPAN occurs by an inner-sphere mechanism, whereas $\mathrm{Cd}(\mathrm{II})$ adsorption on MTPAN is via both surface complexation and As(V)-assisted inner-sphere mechanism. The entrapment of $\mathrm{Cd}(\mathrm{II})$ and $\mathrm{As}(\mathrm{V})$ impurity ions by the functionalized PAN fibers is confirmed by the XPS and FT-IR analyses. Even though the presence of coexistent cations, $\mathrm{Ca}(\mathrm{II})$ and $\mathrm{Mg}(\mathrm{II})$, has been shown to effect $\mathrm{Cd}$ (II) removal by MTPAN, the MTPAN structure shows $>50 \%$ removal efficiency even for minute concentrations $(0.5 \mathrm{ppm})$ of $\mathrm{Cd}$ (II) in the presence of high common ion concentrations (10 ppm). This is very important as these are the conditions generally encountered in real-world (natural) water purification applications. Therefore, the polyacrylonitrile fiber-based novel adsorbent system developed in this study shows potential in using it in the simultaneous removal of $\mathrm{As}(\mathrm{V})$ and $\mathrm{Cd}(\mathrm{II})$ from drinking water in water purification applications.

\section{EXPERIMENTAL SECTION}

4.1. Materials. All chemicals used in this study were of analytical grade. For the preparation of polymer suspensions, polyacrylonitrile (PAN, Sigma Aldrich) with a molecular weight of $10201 \mathrm{~g} / \mathrm{mol}$ and dimethylformamide (99.5\%, DMF, Sigma Aldrich) were used. Magnetite nanoparticles were synthesized using ammonium hydroxide (25\%, Sigma Aldrich), ammonium ferrous sulfate ( $\geq 98 \%$, Sigma Aldrich), and ammonium ferric sulfate (99.0\%, Fischer). Titanium dioxide $\left(\mathrm{TiO}_{2}\right)$ (anatase, 99.7\%) was purchased from Sigma Aldrich. For the adsorption studies, sodium arsenate $\left(\mathrm{Na}_{2} \mathrm{HAsO}_{4}\right.$. $7 \mathrm{H}_{2} \mathrm{O}, \geq 98 \%$, Sigma Aldrich), cadmium nitrate tetrahydrate $\left(\mathrm{Cd}\left(\mathrm{NO}_{3}\right)_{2} \cdot 4 \mathrm{H}_{2} \mathrm{O}, 99 \%\right.$, Riedel-de-Haen), calcium nitrate tetrahydrate $\left(\mathrm{Ca}\left(\mathrm{NO}_{3}\right)_{2} \cdot 4 \mathrm{H}_{2} \mathrm{O}, 99 \%\right.$, Sri Chem), and magnesium nitrate hexahydrate $\left(\mathrm{Mg}\left(\mathrm{NO}_{3}\right)_{2} \cdot 6 \mathrm{H}_{2} \mathrm{O}\right.$, 99\%, Sri Chem) were used, and the aqueous solutions were prepared with ASTM Type I water obtained from Industrial Technology Institute, Sri Lanka.

4.2. Synthesis of Magnetite Nanoparticles. For the preparation of magnetite $\left(\mathrm{Fe}_{3} \mathrm{O}_{4}\right)$ nanoparticles, an alkaline precipitation method was used. A solution of $\mathrm{Fe}^{3+}(0.1 \mathrm{M})$ was mixed with an $\mathrm{Fe}^{2+}(0.1 \mathrm{M})$ solution in a $2: 1$ volume ratio. The $\mathrm{Fe}^{3+} / \mathrm{Fe}^{2+}$ ion solution mixture was purged with $\mathrm{N}_{2}(\mathrm{~g})$ for a few minutes. Next, an excess of an aqueous $5 \mathrm{M} \mathrm{NH} \mathrm{NH}_{4} \mathrm{OH}$ solution was added dropwise to the solution under continuous stirring. The resulting black slurry was centrifuged at $9000 \mathrm{rpm}$ for $45 \mathrm{~min}$, and the black precipitate obtained was dried in air.

4.3. Preparation of Polymer Solutions. PAN/DMF solutions with polymer concentrations of $5 \%(\mathrm{w} / \mathrm{v})$ were prepared ( $0.5 \mathrm{mg}$ of PAN in $8 \mathrm{~mL}$ of DMF), and from them, suspensions of $\mathrm{Fe}_{3} \mathrm{O}_{4} / \mathrm{PAN}$ and $\mathrm{TiO}_{2} / \mathrm{PAN}$ were prepared. The PAN in the DMF solution was stirred at $400 \mathrm{rpm}$ at $90{ }^{\circ} \mathrm{C}$ for $30 \mathrm{~min}$ until obtaining a transparent polymer solution. For the preparation of $\mathrm{PAN} / \mathrm{Fe}_{3} \mathrm{O}_{4} / \mathrm{TiO}_{2}$ (MTPAN) suspensions, the nanoparticles were first dispersed in DMF by stirring for 15 min followed by ultrasonication (UP400S Hielscher probe tip sonicator, diameter: $1.3 \mathrm{~cm}$, operating power output $430 \mathrm{~W}$ at $24 \mathrm{kHz}$ ) for $15 \mathrm{~min}$. A concentrated PAN solution in DMF was added to the nanoparticle dispersion $(0.1 \mathrm{mg}$ of nanoparticles in $2 \mathrm{~mL}$ of DMF) to give a suspension with a total solid content of $6 \% \mathrm{w} / \mathrm{v}$ ( $5 \%$ polymer, $0.5 \% \mathrm{Fe}_{3} \mathrm{O}_{4}, 0.5 \% \mathrm{TiO}_{2}$, i.e., $0.5 \mathrm{mg}$ of PAN and $0.05 \mathrm{mg}$ of each nanoparticle in $10 \mathrm{~mL}$ of DMF). The final mixture was sonicated for another $30 \mathrm{~min}$. Similarly, polymer suspensions of $\mathrm{Fe}_{3} \mathrm{O}_{4} / \mathrm{PAN}$ (MPAN) and $\mathrm{TiO}_{2} /$ PAN (TPAN) were also prepared with a $6 \%(\mathrm{w} / \mathrm{v})$ total solid content ( $5 \%$ polymer, $1 \%$ nanoparticles, i.e., $0.5 \mathrm{mg}$ of PAN and $0.1 \mathrm{mg}$ of $\mathrm{TiO}_{2}$ in $10 \mathrm{~mL}$ of DMF). The PAN suspensions with no nanoparticles impregnated were prepared from the $6 \%(\mathrm{w} / \mathrm{v})$ PAN polymer in DMF $(0.6 \mathrm{mg}$ of PAN in $10 \mathrm{~mL}$ of DMF) to maintain the same total solid content in the solution used for the electrospinning process. For the polymer concentrations of $7 \%(\mathrm{w} / \mathrm{v})$ and $8 \%(\mathrm{w} / \mathrm{v})$ used in optimization of electrospinning conditions (discussed in Section 2.1), polymer concentrations of $6 \%(\mathrm{w} / \mathrm{v})$ and $7 \%$ 
$(\mathrm{w} / \mathrm{v})$ were used, respectively, with $0.5 \%(\mathrm{w} / \mathrm{v})$ of $\mathrm{Fe}_{3} \mathrm{O}_{4}$ and $\mathrm{TiO}_{2}$ (weight measurements were taken in the same way as described earlier). To identify the immobilization of two nanoparticle types in the fiber structures using FT-IR analysis (as discussed in Section 2.2), fibers with $5 \%(\mathrm{w} / \mathrm{v})$ polymer and $1 \%(\mathrm{w} / \mathrm{v})$ of each $\mathrm{Fe}_{3} \mathrm{O}_{4}$ and $\mathrm{TiO}_{2}$ nanoparticles were also prepared following the above-mentioned similar procedure.

4.4. Electrospinning. The polymer suspensions were loaded in a $5 \mathrm{~mL}$ syringe fitted with a $0.3 \mathrm{~mm}$ (23 G) stainless steel needle. The needle was connected to a highvoltage power supply (MATSUSADA Precision Inc.). A flat piece of $\mathrm{Al}$ foil was used as the grounded collector. The solution was dispensed using a syringe pump (New Era Pump systems, NE 300). The electrospinning process was carried out at $25{ }^{\circ} \mathrm{C}$ and $\sim 55 \%$ relative humidity. During optimization, the feed rate was set at 4,8 , and $10 \mu \mathrm{L} / \mathrm{min}$. The voltage was fixed at $15,18,20$, and $25 \mathrm{kV}$, while the distance between the needle tip and the collector was varied from 12 to $15 \mathrm{~cm}$ and $20 \mathrm{~cm}$. The electrospun fiber mats were oven-dried at $45{ }^{\circ} \mathrm{C}$ to remove any residual traces of DMF before further analysis. To select the best electrospinning conditions, morphological analyses were performed using scanning electron microscopy (SEM, Hitachi SU 6600 instrument).

4.5. Characterization. The optimal nanofibers, generated with $6 \%(\mathrm{w} / \mathrm{v})$ polymer/nanoparticle suspensions at $25 \mathrm{kV}$, utilizing a flow rate of $10 \mu \mathrm{L} / \mathrm{min}$ and a working distance of 20 $\mathrm{cm}$, were characterized in detail. Morphological observations were undertaken using SEM, and energy-dispersive spectroscopy (EDX; Oxford Instruments X-Act) analysis was also performed to determine the elemental composition of the synthesized fibers. The surface areas were approximated by $\mathrm{N}_{2}$ adsorption at $77 \mathrm{~K}$ (Beckman Coulter Sorption Analyzer 3100) and calculated using the Brunauer-Emmett-Teller (BET) isotherm model. The samples were degassed at $40{ }^{\circ} \mathrm{C}$ for $24 \mathrm{~h}$, prior to each analysis. Powder X-ray diffraction patterns were collected with the aid of a Bruker D8 FOCUS instrument supplied with $\mathrm{Cu} \mathrm{K} \alpha$ radiation, operating at $25 \mathrm{kV}$ and $30 \mathrm{~mA}$. Fourier transform infrared (FT-IR) spectroscopy was undertaken on a Bruker FT-IR Vertex 80 instrument in the attenuated total reflectance (ATR) mode with a $\mathrm{ZnSe}$ crystal. Transmittance spectra were recorded in the $400-4000 \mathrm{~cm}^{-1}$ wavenumber range with a $4 \mathrm{~cm}^{-1}$ resolution and 32 scans per sample.

4.6. Thermal Stabilization. The thermal characteristics of the MTPAN fibers as synthesized in Section 4.5 were analyzed using thermogravimetric analysis (TGA; TA Instruments, SDT Q600 instrument) in oxygen and nitrogen atmospheres, at a heating rate of $5{ }^{\circ} \mathrm{C} / \mathrm{min}$. The same MTPAN nanofibers were thermally stabilized at three different conditions: (1) fibers were heated up to $275^{\circ} \mathrm{C}$ at a $5 \mathrm{C} / \mathrm{min}$ heating rate in air and held for $30 \mathrm{~min}$; (2) fibers stabilized at $275^{\circ} \mathrm{C}$ were heated to $700{ }^{\circ} \mathrm{C}$ at a $5{ }^{\circ} \mathrm{C} / \mathrm{min}$ rate under $\mathrm{N}_{2}$ and held for $30 \mathrm{~min}$; and (3) fibers consecutively stabilized at $275{ }^{\circ} \mathrm{C}$ and $700{ }^{\circ} \mathrm{C}$ were further heated to $1100^{\circ} \mathrm{C}$ at $5{ }^{\circ} \mathrm{C} / \mathrm{min}$ under $\mathrm{N}_{2}$ and held for 30 min. ${ }^{68}$ After each carbonization step, the percentage weight loss was calculated. Further, the effect of pyrolysis temperature on defect removal in the fibers was studied using Raman spectroscopy (Bruker Senterra instrument).

4.7. Adsorption Experiments. Adsorption studies included the isotherm analyses, measuring the adsorption capacity at different $\mathrm{pHs}$, and studying the effect of other coions present in natural water bodies on $\mathrm{AsO}_{4}{ }^{3-}$ and $\mathrm{Cd}^{2+}$ adsorption. For the static adsorption studies, the fiber composites were used in their mat forms rather than using them as membranes. In all experiments, a $0.2 \mathrm{~g} / \mathrm{L}$ adsorbent dosage was used and experiments were conducted at room temperature $\left(25^{\circ} \mathrm{C}\right)$. For isotherm analysis, the MTPAN, MPAN, TPAN, and PAN fibers thermally stabilized at $275^{\circ} \mathrm{C}$ in air were immersed in $10.0 \mathrm{~mL}$ aliquots of $\mathrm{As}(\mathrm{V})$ and $\mathrm{Cd}(\mathrm{II})$ solutions with concentrations of $0.1,0.2,0.4,0.6,1.0,2.0$, and $5.0 \mathrm{ppm}$ for $22 \mathrm{~h}$, using a shaker (Benchmark Scientific, IncuShaker Mini). The adsorption reactions were terminated by filtering the solutions using $0.22 \mu \mathrm{m}$ nylon syringe filters. The $\mathrm{As}(\mathrm{V})$ and $\mathrm{Cd}(\mathrm{II})$ concentrations before and after adsorption processes were quantified using inductively coupled plasmamass spectrometry (ICP-MS, Agilent 7900 instrument). In assessing the effect of $\mathrm{pH}, \mathrm{MTPAN}$ and PAN fibers were reacted with $5 \mathrm{ppm} \mathrm{As}(\mathrm{V})$ and $5 \mathrm{ppm} \mathrm{Cd}(\mathrm{II})$ solutions separately for $20 \mathrm{hrs}$, with the initial $\mathrm{pH}$ set at 3, 5, 7, and 9 . The $\mathrm{pH}$ of the medium after the reaction was also measured, and the point of zero charge $\left(\mathrm{pH}_{\mathrm{pzc}}\right)$ was estimated using the pH drift method. ${ }^{69}$ The MTPAN and MPAN fibers after $\mathrm{Cd}(\mathrm{II})$ and $\mathrm{As}(\mathrm{V})$ adsorption studies were analyzed by SEM, EDX, and FT-IR. The effect of the presence of co-ions such as $\mathrm{Ca}(\mathrm{II})$ and $\mathrm{Mg}$ (II) was studied by conducting the adsorption experiments for $20 \mathrm{hrs}$, in aliquots of solutions containing each of $\mathrm{As}(\mathrm{V})$ and $\mathrm{Cd}(\mathrm{II})$ at $0.5 \mathrm{ppm}$ concentration and $\mathrm{Ca}(\mathrm{II})$ and $\mathrm{Mg}$ (II) at $0,10,25,50$, and $100 \mathrm{ppm}$ concentrations. Elemental compositions of fiber surfaces after coadsorption of $\mathrm{Cd}(\mathrm{II})$ and $\mathrm{As}(\mathrm{V})$ were analyzed using X-ray photoelectron spectroscopy (XPS) with the EXCALABXi ${ }^{+}$hemispherical electron energy analyzer (Thermo Fisher Scientific, the United States). The incident radiation was monochromatic $\mathrm{Al} \mathrm{K} \alpha \mathrm{X}$ rays $(1486.6 \mathrm{eV})$ with a spot size of $900 \mu \mathrm{m}$. Survey scans and high-resolution scans were collected with pass energies of 150 and $20 \mathrm{eV}$ and with step sizes of 1.0 and $0.05 \mathrm{eV}$, respectively.

\section{ASSOCIATED CONTENT}

\section{SI Supporting Information}

The Supporting Information is available free of charge at https://pubs.acs.org/doi/10.1021/acsomega.1c04238.

SEM images capturing the morphological differences of fibers during various electrospinning conditions; SEM of magnetite and anatase nanoparticles; histograms of the electrospun fiber diameters; EDX analysis, BET isotherms, and FT-IR and Raman spectra of fibers; data on the effect of $\mathrm{pH}$ on adsorption; Langmuir and Freundlich adsorption isotherms; FT-IR, EDX, and XPS data of fibers after salt adsorption (PDF)

\section{AUTHOR INFORMATION}

\section{Corresponding Author}

K. M. Nalin de Silva - Centre for Advanced Materials and Devices (CAMD), Department of Chemistry, University of Colombo, Colombo 00300, Sri Lanka; (1) orcid.org/00000003-3219-3233; Email: kmnd@chem.cmb.ac.lk

\section{Authors}

Induni W. Siriwardane - Centre for Advanced Materials and Devices (CAMD), Department of Chemistry, University of Colombo, Colombo 00300, Sri Lanka; Sri Lanka Institute of Nanotechnology (SLINTEC), Nanotechnology and Science Park, Homagama 10200, Sri Lanka

Chanaka Sandaruwan - Sri Lanka Institute of Nanotechnology (SLINTEC), Nanotechnology and Science 
Park, Homagama 10200, Sri Lanka; 이잉.org/00000001-6102-096X

Rohini M. de Silva - Centre for Advanced Materials and Devices (CAMD), Department of Chemistry, University of Colombo, Colombo 00300, Sri Lanka

Gareth R. Williams - UCL School of Pharmacy, University College London, London WC1N 1AX, United Kingdom; 응 orcid.org/0000-0002-3066-2860

Sebastian J. Gurgul - UCL School of Pharmacy, University College London, London WC1N 1AX, United Kingdom

Karolina Dziemidowicz - UCL School of Pharmacy, University College London, London WC1N 1AX, United Kingdom

Complete contact information is available at: https://pubs.acs.org/10.1021/acsomega.1c04238

\section{Notes}

The authors declare no competing financial interest.

\section{ACKNOWLEDGMENTS}

This work was entirely funded by the Sri Lanka Institute of Nanotechnology (SLINTEC), Homagama, Sri Lanka. Further, the authors acknowledge Dr. Nadeeka Tissera and Dr. Ruchira Wijesena from SLINTEC for the assistance provided in assembling the customized electrospinning apparatus.

\section{REFERENCES}

(1) Bai, B.; Mi, X.; Xiang, X.; Heiden, P. A.; Heldt, C. L. Nonenveloped virus reduction with quaternized chitosan nanofibers containing graphene. Carbohydr. Res. 2013, 380, 137-142.

(2) Wen, Q.; Di, J.; Zhao, Y.; Wang, Y.; Jiang, L.; Yu, J. Flexible inorganic nanofibrous membranes with hierarchical porosity for efficient water purification. Chem. Sci. 2013, 4, 4378-4382.

(3) Fernando, M. S.; Wimalasiri, A. K. D. V. K.; Dziemidowicz, K.; Williams, G. R.; Koswattage, K. R.; Dissanayake, D. P.; de Silva, K. M. N.; de Silva, R. M. Biopolymer-Based Nanohydroxyapatite Composites for the Removal of Fluoride, Lead, Cadmium, and Arsenic from Water. ACS Omega 2021, 6, 8517-8530.

(4) Wimalasiri, A. K. D. V. K.; Fernando, M. S.; Dziemidowicz, K.; Williams, G. R.; Koswattage, K. R.; Dissanayake, D. P.; de Silva, K. M. N.; de Silva, R. M. Structure-Activity Relationship of LanthanideIncorporated Nano-Hydroxyapatite for the Adsorption of Fluoride and Lead. ACS Omega 2021, 6, 13527-13543.

(5) Lankathilaka, K. P. W.; de Silva, R. M.; Mantilaka, M. M. M. G. P. G.; de Silva, K. M. N. Magnetite nanoparticles incorporated porous kaolin as a superior heavy metal sorbent for water purification. Groundwater Sustainable Dev. 2021, 14, No. 100606.

(6) Jayaweera, H.; Siriwardane, I.; de Silva, K. M. N.; de Silva, R. M. Synthesis of multifunctional activated carbon nanocomposite comprising biocompatible flake nano hydroxyapatite and natural turmeric extract for the removal of bacteria and lead ions from aqueous solution. Chem. Cent. J. 2018, 12, 1-14.

(7) Siriwardane, I. W.; Rathuwadu, N. P. W.; Dahanayake, D.; Sandaruwan, C.; de Silva, R. M.; de Silva, K. M. N. Nano-manganese oxide and reduced graphene oxide-incorporated polyacrylonitrile fiber mats as an electrode material for capacitive deionization (CDI) technology. Nanoscale Adv. 2021, 3, 2585-2597.

(8) Suja, P. S.; Reshmi, C. R.; Sagitha, P.; Sujith, A. Electrospun Nanofibrous Membranes for Water Purification. Polym. Rev. 2017, 57, 467-504.

(9) Ulbricht, M. Advanced functional polymer membranes. Polymer 2006, 47, 2217-2262.

(10) Jiang, J.; Zhu, L.; Zhu, L.; Zhang, H.; Zhu, B.; Xu, Y. Antifouling and Antimicrobial Polymer Membranes Based on Bioinspired Polydopamine and Strong Hydrogen-Bonded Poly(N- vinyl pyrrolidone). ACS Appl. Mater. Interfaces. 2013, 5, 1289512904.

(11) Feng, C.; Khulbe, K. C.; Matsuura, T.; Tabe, S.; Ismail, A. F. Preparation and characterization of electro-spun nanofiber membranes and their possible applications in water treatment. Sep. Purif. Technol. 2013, 102, 118-135.

(12) Ramakrishna, S.; Fujihara, K.; Teo, W.-E.; Yong, T.; Ma, Z.; Ramaseshan, R. Electrospun nanofibers: solving global issues. Mater. Today. 2006, 9, 40-50.

(13) Gopal, R.; Kaur, S.; Ma, Z.; Chan, C.; Ramakrishna, S.; Matsuura, T. Electrospun nanofibrous filtration membrane. J. Membr. Sci. 2006, 281, 581-586.

(14) He, T.; Zhou, W.; Bahi, A.; Yang, H.; Ko, F. High permeability of ultrafiltration membranes based on electrospun PVDF modified by nanosized zeolite hybrid membrane scaffolds under low pressure. Chem. Eng. J. 2014, 252, 327-336.

(15) Lee, J.-W.; Jung, J.; Cho, Y. H.; Yadav, S. K.; Baek, K. Y.; Park, H. B.; Hong, S. M.; Koo, C. M. Fouling-Tolerant Nanofibrous Polymer Membranes for Water Treatment. ACS Appl. Mater. Interfaces 2014, 6, 14600-14607.

(16) Homaeigohar, S.; Koll, J.; Lilleodden, E. T.; Elbahri, M. The solvent induced interfiber adhesion and its influence on the mechanical and filtration properties of polyethersulfone electrospun nanofibrous microfiltration membranes. Sep. Purif. Technol. 2012, 98, $456-463$.

(17) Homaeigohar, S. S.; Elbahri, M. Novel compaction resistant and ductile nanocomposite nanofibrous microfiltration membranes. $J$. Colloid Interface Sci. 2012, 372, 6-15.

(18) Cao, X.; Huang, M.; Ding, B.; Yu, J.; Sun, G. Robust polyacrylonitrile nanofibrous membrane reinforced with jute cellulose nanowhiskers for water purification. Desalination 2013, 316, 120-126.

(19) Mahanta, N.; Valiyaveettil, S. Functionalized poly(vinyl alcohol) based nanofibers for the removal of arsenic from water. RSC Adv. 2013, 3, 2776-2783.

(20) Stephen, M.; Catherine, N.; Brenda, M.; Andrew, K.; Leslie, P.; Corrine, G. Oxolane-2,5-dione modified electrospun cellulose nanofibers for heavy metals adsorption. J. Hazard. Mater. 2011, 192, 922927.

(21) Pant, H. R.; Kim, H. J.; Joshi, M. K.; Pant, B.; Park, C. H.; Kim, J. I.; Hui, K. S.; Kim, C. S. One-step fabrication of multifunctional composite polyurethane spider-web-like nanofibrous membrane for water purification. J. Hazard. Mater. 2014, 264, 25-33.

(22) Oh, N.-W.; Jegal, J.; Lee, K.-H. Preparation and characterization of nanofiltration composite membranes using polyacrylonitrile (PAN). II. Preparation and characterization of polyamide composite membranes. J. Appl. Polym. Sci. 2001, 80, 2729-2736.

(23) Shunkevich, A. A.; Akulich, Z. I.; Mediak, G. V.; Soldatov, V. S. Acid-base properties of ion exchangers. III. Anion exchangers on the basis of polyacrylonitrile fiber. React. Funct. Polym. 2005, 63, 27-34. (24) Shen, J.-n.; Li, D.-d.; Jiang, F.-y.; Qiu, J.-h.; Gao, C.-j. Purification and concentration of collagen by charged ultrafiltration membrane of hydrophilic polyacrylonitrile blend. Sep. Purif. Technol. 2009, 66, 257-262.

(25) Petrova, S. P.; Stoychev, P. A. Ultrafiltration purification of waters contaminated with bifunctional reactive dyes. Desalination 2003, 154, 247-252.

(26) Sentana, I.; De La Rubia, M. A.; Rodríguez, M.; Sentana, E.; Prats, D. Removal of natural organic matter by cationic and anionic polyacrylonitrile membranes. The effect of pressure, ionic strength and pH. Sep. Purif. Technol. 2009, 68, 305-311.

(27) Vaidya, S. R.; Kharul, U. K.; Chitambar, S. D.; Wanjale, S. D.; Bhole, Y. S. Removal of hepatitis A virus from water by polyacrylonitrile-based ultrafiltration membranes. J. Virol. Methods 2004, 119, 7-9.

(28) Sato, A.; Wang, R.; Ma, H.; Hsiao, B. S.; Chu, B. Novel nanofibrous scaffolds for water filtration with bacteria and virus removal capability. J. Electron Microsc. 2011, 60, 201-209.

(29) Jung, B. Preparation of hydrophilic polyacrylonitrile blend membranes for ultrafiltration. J. Membr. Sci. 2004, 229, 129-136. 
(30) Yoon, K.; Hsiao, B. S.; Chu, B. High flux ultrafiltration nanofibrous membranes based on polyacrylonitrile electrospun scaffolds and crosslinked polyvinyl alcohol coating. J. Membr. Sci. 2009, 338, 145-152.

(31) Lohokare, H. R.; Kumbharkar, S. C.; Bhole, Y. S.; Kharul, U. K. Surface modification of polyacrylonitrile based ultrafiltration membrane. J. Appl. Polym. Sci. 2006, 101, 4378-4385.

(32) Makaremi, M.; De Silva, R. T.; Pasbakhsh, P. Electrospun Nanofibrous Membranes of Polyacrylonitrile/Halloysite with Superior Water Filtration Ability. J. Phys. Chem. C 2015, 119, 7949-7958.

(33) Panda, S. R.; De, S. Preparation, characterization and antifouling properties of polyacrylonitrile/polyurethane blend membranes for water purification. RSC Adv. 2015, 5, 23599-23612.

(34) Zhao, X.; Su, Y.; Chen, W.; Peng, J.; Jiang, Z. Grafting perfluoroalkyl groups onto polyacrylonitrile membrane surface for improved fouling release property. J. Membr. Sci. 2012, 415-416, 824834.

(35) Asatekin, A.; Olivetti, E. A.; Mayes, A. M. Fouling resistant, high flux nanofiltration membranes from polyacrylonitrile-graftpoly(ethylene oxide). J. Membr. Sci. 2009, 332, 6-12.

(36) Kiani, G. R.; Sheikhloie, H.; Arsalani, N. Heavy metal ion removal from aqueous solutions by functionalized polyacrylonitrile. Desalination 2011, 269, 266-270.

(37) Park, Y.; Lee, Y.-C.; Shin, W. S.; Choi, S.-J. Removal of cobalt, strontium and cesium from radioactive laundry wastewater by ammonium molybdophosphate-polyacrylonitrile (AMP-PAN). Chem. Eng. J. 2010, 162, 685-695.

(38) Saeed, K.; Park, S.-Y.; Oh, T.-J. Preparation of hydrazinemodified polyacrylonitrile nanofibers for the extraction of metal ions from aqueous media. J. Appl. Polym. Sci. 2011, 121, 869-873.

(39) Zhao, Q.; Cao, T. Polyacrylonitrile/Silica Nanospheres with Three- Dimensional Interpenetrating Network Structure and Their Application for Removal of $\mathrm{Pb}(\mathrm{II})$ from Water. Ind. Eng. Chem. Res. 2012, 51, 4952-4957.

(40) Nilchi, A.; Garmarodi, S. R.; Darzi, S. J. Removal of arsenic from aqueous solutions by an adsorption process with titania-silica binary oxide nanoparticle loaded polyacrylonitrile polymer. J. Appl. Polym. Sci. 2011, 119, 3495-3503.

(41) Molinari, R.; Mungari, M.; Drioli, E.; Di Paola, A.; Loddo, V.; Palmisano, L.; Schiavello, M. Study on a photocatalytic membrane reactor for water purification. Catal. Today. 2000, 55, 71-78.

(42) Tissera, N. D.; Wijesena, R. N.; Sandaruwan, C. S.; de Silva, R. M.; de Alwis, A.; de Silva, K. M. N. Photocatalytic activity of $\mathrm{ZnO}$ nanoparticle encapsulated poly(acrylonitrile) nanofibers. Mater. Chem. Phys. 2018, 204, 195-206.

(43) İnan, S.; Altaş, Y. Preparation of zirconium-manganese oxide/ polyacrylonitrile $(\mathrm{Zr}-\mathrm{Mn}$ oxide/PAN) composite spheres and the investigation of $\mathrm{Sr}(\mathrm{II})$ sorption by experimental design. Chem. Eng. J. 2011, 168, 1263-1271.

(44) Lin, Y.; Cai, W.; Tian, X.; Liu, X.; Wang, G.; Liang, C. Polyacrylonitrile/ferrous chloride composite porous nanofibers and their strong Cr-removal performance. J. Mater. Chem. 2011, 21, 991997.

(45) Yavuz, M.; Gode, F.; Pehlivan, E.; Ozmert, S.; Sharma, Y. C. An economic removal of $\mathrm{Cu} 2+$ and $\mathrm{Cr} 3+$ on the new adsorbents: Pumice and polyacrylonitrile/pumice composite. Chem. Eng. J. 2008, 137, 453-461.

(46) Jayatilake, N.; Mendis, S.; Maheepala, P.; Mehta, F. R. Chronic kidney disease of uncertain aetiology: prevalence and causative factors in a developing country. BMC Nephrol. 2013, 14, No. 180.

(47) Ratnayake, S.; Badurdeen, Z.; Nanayakkara, N.; Abeysekara, T.; Ratnatunga, N.; Kumarasiri, R. Screening for chronic kidney disease of uncertain aetiology in Sri Lanka: usability of surrogate biomarkers over dipstick proteinuria. BMC Nephrol. 2017, 18, No. 199.

(48) Beduk, F. Superparamagnetic nanomaterial $\mathrm{Fe}_{3} \mathrm{O}_{4}-\mathrm{TiO}_{2}$ for the removal of $\mathrm{As}(\mathrm{V})$ and $\mathrm{As}(\mathrm{III})$ from aqueous solutions. Environ. Technol. 2016, 37, 1790-1801.
(49) Jiang, W.; Lv, J.; Luo, L.; Yang, K.; Lin, Y.; Hu, F.; Zhang, J.; Zhang, S. Arsenate and cadmium co-adsorption and co-precipitation on goethite. J. Hazard. Mater. 2013, 262, 55-63.

(50) Zhang, S.; Li, X.-y.; Chen, J. P. Preparation and evaluation of a magnetite-doped activated carbon fiber for enhanced arsenic removal. Carbon 2010, 48, 60-67.

(51) Fitzer, E.; Frohs, W.; Heine, M. Optimization of stabilization and carbonization treatment of PAN fibres and structural characterization of the resulting carbon fibres. Carbon 1986, 24, 387-395.

(52) Newcombe, G.; Hayes, R.; Drikas, M. Granular activated carbon: Importance of surface properties in the adsorption of naturally occurring organics. Colloids Surf., A 1993, 78, 65-71.

(53) Li, Z.; Wang, C. Effects of Working Parameters on Electrospinning. In One-Dimensional nanostructures: Electrospinning Technique and Unique Nanofibers; Li, Z.; Wang, C., Eds.; Springer Berlin Heidelberg: Berlin, Heidelberg, 2013; pp 15-28.

(54) Zhang, D.; Karki, A. B.; Rutman, D.; Young, D. P.; Wang, A.; Cocke, D.; Ho, T. H.; Guo, Z. Electrospun polyacrylonitrile nanocomposite fibers reinforced with $\mathrm{Fe} 3 \mathrm{O} 4$ nanoparticles: Fabrication and property analysis. Polymer 2009, 50, 4189-4198.

(55) Pirlot, C.; Willems, I.; Fonseca, A.; Nagy, J. B.; Delhalle, J. Preparation and Characterization of Carbon Nanotube/Polyacrylonitrile Composites. Adv. Eng. Mater. 2002, 4, 109-114.

(56) Petcharoen, K.; Sirivat, A. Synthesis and characterization of magnetite nanoparticles via the chemical co-precipitation method. Mater. Sci. Eng., B 2012, 177, 421-427.

(57) Porkodi, K.; Arokiamary, S. D. Synthesis and spectroscopic characterization of nanostructured anatase titania: A photocatalyst. Mater. Charact. 2007, 58, 495-503.

(58) Rahaman, M. S. A.; Ismail, A. F.; Mustafa, A. A review of heat treatment on polyacrylonitrile fiber. Polym. Degrad. Stab. 2007, 92, $1421-1432$

(59) Ferrari, A. C. Raman spectroscopy of graphene and graphite: Disorder, electron-phonon coupling, doping and nonadiabatic effects. Solid State Commun. 2007, 143, 47-57.

(60) Castiglioni, C.; Negri, F.; Rigolio, M.; Zerbi, G. Raman activation in disordered graphites of the $\mathrm{Al}^{\prime}$ symmetry forbidden $\mathrm{k} \neq 0$ phonon: The origin of the D line. J. Chem. Phys. 2001, 115, 37693778.

(61) Zhang, S.; Li, X.-y.; Chen, J. P. Preparation and evaluation of a magnetite-doped activated carbon fiber for enhanced arsenic removal. Carbon 2010, 48, 60-67.

(62) Jolivet, J. P. Metal Oxide Chemistry and Synthesis. From Solution to Solid State; John Wiley \& Sons Ltd., 2000.

(63) Gao, Y.; Wahi, R.; Kan, A. T.; Falkner, J. C.; Colvin, V. L.; Tomson, M. B. Adsorption of Cadmium on Anatase NanoparticlesEffect of Crystal Size and pH. Langmuir 2004, 20, 95859593

(64) Liu, C.-H.; Chuang, Y.-H.; Chen, T.-Y.; Tian, Y.; Li, H.; Wang, M.-K.; Zhang, W. Mechanism of Arsenic Adsorption on Magnetite Nanoparticles from Water: Thermodynamic and Spectroscopic Studies. Environ. Sci. Technol. 2015, 49, 7726-7734.

(65) Pena, M.; Meng, X.; Korfiatis, G. P.; Jing, C. Adsorption mechanism of arsenic on nanocrystalline titanium dioxide. Environ. Sci. Technol. 2006, 40, 1257-62.

(66) Wang, X. S.; Liu, F.; Lu, H. J.; Zhang, P.; Zhou, H. Y. Adsorption kinetics of Cd (II) from aqueous solution by magnetite. Desalin. Water Treat. 2011, 36, 203-209.

(67) Prakash, T.; Arunkumar, T.; Sathya Raj, D.; Jayaprakash, R. Surfactant-liaised Variation in CdO Nanocomposites Morphology. Phys. Procedia 2013, 49, 36-43.

(68) Gomez, M. A.; Assaaoudi, H.; Becze, L.; Cutler, J. N.; Demopoulos, G. P. Vibrational spectroscopy study of hydrothermally produced scorodite $\left(\mathrm{FeAsO}_{4} \cdot 2 \mathrm{H}_{2} \mathrm{O}\right)$, ferric arsenate sub-hydrate (FAsH; $\mathrm{FeAsO} 4 \cdot 0.75 \mathrm{H} 2 \mathrm{O})$ and basic ferric arsenate sulfate (BFAS; $\mathrm{Fe}[(\mathrm{AsO} 4) 1-\mathrm{x}(\mathrm{SO} 4) \mathrm{x}(\mathrm{OH}) \mathrm{x}] \cdot \mathrm{wH} 2 \mathrm{O})$. J. Raman Spectrosc. 2010, 41, $212-221$.

(69) Teutli-Sequeira, A.; Solache-Ríos, M.; Olguín, M. T. Influence of $\mathrm{Na}^{+}, \mathrm{Ca}^{2+}, \mathrm{Mg}^{2+}$ and $\mathrm{NH}^{4+}$ on the sorption behavior of $\mathrm{Cd}^{2+}$ from 
aqueous solutions by a Mexican zeolitic material. Hydrometallurgy 2009, 97, 46-52. 